\title{
Factors Determining Disease Duration in Alzheimer's Disease: A Postmortem Study of 103 Cases Using the Kaplan-Meier Estimator and Cox Regression
}

\author{
R. A. Armstrong \\ Vision Sciences, Aston University, Birmingham B4 7ET, UK \\ Correspondence should be addressed to R. A. Armstrong; r.a.armstrong@aston.ac.uk
}

Received 26 April 2013; Revised 5 November 2013; Accepted 24 November 2013; Published 22 January 2014

Academic Editor: Maurizio Gallucci

Copyright (c) 2014 R. A. Armstrong. This is an open access article distributed under the Creative Commons Attribution License, which permits unrestricted use, distribution, and reproduction in any medium, provided the original work is properly cited.

Factors associated with duration of dementia in a consecutive series of 103 Alzheimer's disease (AD) cases were studied using the Kaplan-Meier estimator and Cox regression analysis (proportional hazard model). Mean disease duration was 7.1 years (range: 6 weeks-30 years, standard deviation $=5.18$ ); $25 \%$ of cases died within four years, $50 \%$ within 6.9 years, and $75 \%$ within 10 years. Familial AD cases (FAD) had a longer duration than sporadic cases (SAD), especially cases linked to presenilin (PSEN) genes. No significant differences in duration were associated with age, sex, or apolipoprotein E (Apo E) genotype. Duration was reduced in cases with arterial hypertension. Cox regression analysis suggested longer duration was associated with an earlier disease onset and increased senile plaque (SP) and neurofibrillary tangle (NFT) pathology in the orbital gyrus (OrG), CA1 sector of the hippocampus, and nucleus basalis of Meynert (NBM). The data suggest shorter disease duration in SAD and in cases with hypertensive comorbidity. In addition, degree of neuropathology did not influence survival, but spread of SP/NFT pathology into the frontal lobe, hippocampus, and basal forebrain was associated with longer disease duration.

\section{Introduction}

Studies of the life expectancy of patients with Alzheimer's disease $(\mathrm{AD})$ are important in calculating prevalence rates while identifying factors that influence survival is useful both in counseling patients and their families and in public health planning [1-3]. Many published studies, however, suggest that survival rates vary considerably in $\mathrm{AD}$ and depend on numerous factors [3]. Hence, survival may depend on age at diagnosis, sex, disease subtype, and severity of progression of the disease.

$\mathrm{AD}$ is a heterogeneous disease [4-6] and survival may depend on subtype [7]. First, AD consists of sporadic (SAD) and familial forms (FAD), most cases of the latter being associated with mutations of either the amyloid precursor protein $(A P P)$ gene on chromosome $21[8,9]$ or the presenilin genes PSEN1 [10] and PSEN2 [11] on chromosomes 14 and 1, respectively. In addition, allelic variation in the apolipoprotein $E$ (Apo E) gene on chromosome 19 has been identified as an important risk factor, especially in late-onset $\mathrm{AD}$ individuals having 2-3 times the frequency of allele $\varepsilon 4$ compared with nondemented elderly controls [12]. Second, more complex forms of $\mathrm{AD}$ have been described, for example, $\mathrm{AD}$ in combination with parkinsonism [13] or dementia with Lewy bodies (DLB/AD) [14], with significant degeneration of white matter [15] or with capillary amyloid angiopathy (CAA). Hence, the presence of one or more comorbidities may significantly affect survival of $\mathrm{AD}$ patients. Third, studies suggest at least two distinct types of disease progression in $\mathrm{AD}$, namely, a rapidly progressive subtype with a median survival time of 10 months and a subtype characterized by a much slower progression [16-18].

The objective of the present study was to investigate the relationship between genetics, demography, neuropathology, comorbidity, and disease duration in $103 \mathrm{AD}$ cases. The Kaplan-Meier estimator and Cox regression analysis (proportional hazard model) were used to study the survival function of the AD patients and to test specific hypotheses [19-21]. 
TABLE 1: Demographic details of the 103 cases used in the study ( $N$ : number of cases; FAD: familial Alzheimer's disease; SAD: sporadic Alzheimer's disease). Data for age at death, duration, and disease onset are means with range and standard deviations in parentheses.

\begin{tabular}{llccr}
\hline Patient group & $N$ & Age at death (years) & Duration (years) & Onset (years) \\
\hline Early-onset FAD & 19 & $61.9(46-74,10.8)$ & $11.1(3-20,6.5)$ & $50.7(38-59,6.5)$ \\
Early-onset SAD & 22 & $70.4(57-88,11.1)$ & $16.0(6-30,9.3)$ & $54.4(49-58,4.2)$ \\
Late-onset FAD & 12 & $77.4(70-85,5.1)$ & $7.0(1-15,4.6)$ & $70.4(61-84,7.6)$ \\
Late-onset SAD & 50 & $80.1(70-98,6.6)$ & $6.8(1-21,4.5)$ & $73.5(62-93,7.2)$ \\
\hline
\end{tabular}

\section{Materials and Methods}

2.1. Cases. The study population comprised a series of 103 consecutive cases of AD diagnosed at the Department of Neuropathology, University of Washington, Seattle, USA (Table 1) [6]. Informed consent was given for the removal of all brain tissue according to the Declaration of Helsinki. AD cases all fulfilled "National Institute of Neurological and Communicative Disorders and Stroke and the Alzheimer Disease and Related Disorders Association" (NINCDS/ADRDA) criteria for probable $\mathrm{AD}$ [22] and were neuropathologically verified using "Consortium to Establish a Registry of Alzheimer Disease" (CERAD) criteria [23] and National Institute on Aging and Reagan Institute criteria [24]. All cases conformed to stage V or VI of the Braak staging system $[25,26]$. The family history of all cases was examined and those with at least one or more first-degree relatives affected were regarded as FAD. Disease duration was measured from the onset of dementia, which was determined by clinical assessment, and defined as cognitive dysfunction sufficiently severe to impair activities of daily living. Of the 103 cases, 19/103 (18\%) were earlyonset ( $\leq 65$ yrs) FAD, 12/103 (11.6\%) were late-onset ( $>65$ yrs) FAD, 22/103 (21\%) were early-onset SAD, and 50/103 (49\%) were late-onset $S A D$. Nine of the early-onset FAD cases were linked to PSEN genes, four cases to PSEN1, and five cases to PSEN2. Apo E genotype was determined for a subset of $40 / 103$ of the cases with the following distribution of genotypes: $\varepsilon 2 / 3$ $(n=1), \varepsilon 3 / 3(n=12), \varepsilon 2 / 4(n=3), \varepsilon 3 / 4(n=18)$, and $\varepsilon 4 / 4$ $(n=6)$.

2.2. Neuropathology. Total brain weight was measured at postmortem. In addition, the abundance of senile plaques (SP) and neurofibrillary tangles (NFT), the signature pathological lesions of $\mathrm{AD}[23,27]$, was measured in 22 cortical and subcortical brain areas from each case (Table 2). The quantitative assessment of SP and NFT was based on examination of tissue sections stained by silver impregnation methods (Holmes, Bielschowsky) which stain mature "neuritic" and "classic" SP and NFT [6]. Preamyloid or diffuse plaques are not consistently labeled by these methods. In each region, 10, $50 \times 50 \mu \mathrm{m}$ sample fields were located at random. The abundance of SP and NFT within each field was assessed using a semiquantitative scale [28]: $0=$ none, $1=$ mild, $2=$ moderate, and 3 = severe. The abundance scores of the SP and NFT were averaged to give a single abundance score for each brain area and rounded up to the nearest whole number. The mean abundance score of the SP/NFT derived from all brain areas studied was used as a measure of the overall severity of the pathology in each case.
TABLE 2: Brain regions and areas studied.

\begin{tabular}{llc}
\hline Brain region & Area studied & Abbreviation \\
\hline \multirow{4}{*}{ Frontal } & Superior frontal gyrus & SFG \\
& Orbital gyrus & OrG \\
& Gyrus rectus & GyR \\
& Cingulate gyrus & CgG \\
\hline Perisylvian & Insula/claustrum & In/Cl \\
\hline \multirow{5}{*}{ Temporal } & Superior temporal gyrus & STG \\
& Parahippocampal gyrus & PHG \\
& Hippocampus, CA1 & CA1 \\
& Dentate gyrus & DG \\
& Amygdala & Am \\
\hline Parietal & Superior parietal lobe & SPL \\
\hline \multirow{5}{*}{ Occipital } & Visual cortex (B17/B18) & OC \\
& Thalamus & Th \\
& Lateral geniculate nucleus & LGN \\
& Basal ganglia & BG \\
& Substantia nigra & SN \\
& Nucleus basalis of Meynert & NBM \\
& Ventral tegmentum & VT \\
& Raphe nucleus & RaN \\
& Mamillary bodies & MB \\
& Hypothalamus & HyP \\
& Cerebellum &
\end{tabular}

2.3. Comorbidity. Comorbidity data [4] were obtained from postmortem records and divided into two groups: (1) neurological comorbidity, for example, associated parkinsonism, amyotrophic lateral sclerosis (ALS), Pick's disease (PiD), Creutzfeldt-Jakob disease (CJD), stroke, infarct, aneurysm, hydrocephalus, motor neuron disease (MND), or tumor, and (2) nonneurological comorbidity, for example, cardiovascular disease (CVD), arterial hypertension, respiratory disease, malignant disease, diabetes, and anemia. A number of aspects of comorbidity were tested against survival of AD patients: (1) the presence or absence of a neurological or nonneurological comorbidity, (2) the frequency of neurological or nonneurological comorbidities recorded for each case, and (3) the individual types of neurological and nonneurological comorbidity which were present in at least six cases.

2.4. Data Analysis. The Kaplan-Meier estimator ("product limit estimator") was used to study the overall pattern of survival among the 103 cases and is the fraction of patients which survive for a certain period after onset of dementia. In typical 
applications, the data can be grouped into subtypes and the effect of the grouping factor on disease duration estimated. Where two groups were present, for example, FAD/SAD, male/female, or presence/absence of comorbidity, duration was compared using the Gehan-Wilcoxon two-sample test. With more than two groups, duration was compared using the chi-square $\left(\chi^{2}\right)$ test. The Cox proportional hazard model allows the relationship between disease duration and continuously measured variables to be tested and was applied to (1) demographic variables such as patient age and disease onset, genetic factors such as Apo E score (the sum of the two alleles), and the frequency of one or more neurological and nonneurological comorbidities, (2) measures of overall neuropathology such as mean severity score and the number of brain areas affected by SP/NFT, and (3) abundance scores of SP and NFT in each of the 22 brain areas investigated. The effect of disease onset may be biased by the presence of cases linked to PSEN mutations, and hence, the effect of this variable was also assessed with the PSEN mutation cases omitted. Statistical significance was based on " $t$ " and the "Wald" statistic.

\section{Results}

Mean disease duration of the $103 \mathrm{AD}$ cases was 7.1 years (range: 6 weeks-30 years, standard deviation $=5.18$ ). The survival function for all 103 cases studied is shown in Figure 1. The data indicate that $25 \%$ of cases died within four years, $50 \%$ within 6.9 years, and $75 \%$ within 10 years after onset.

Gehan-Wilcoxon test suggested a significant difference in disease duration between SAD and all FAD cases $(\mathrm{G}-\mathrm{W}=$ 2.51, $P<0.05)$. When cases were separated into SAD, cases linked to PSEN mutations, and all remaining FAD (Figure 2), the PSEN cases, on average, exhibited the greatest disease duration $\left(\chi^{2}=7.13, P<0.01\right)$. There were no significant differences in duration when the data were grouped according to sex $(\mathrm{G}-\mathrm{W}=0.58, P>0.05)$, the presence/absence of neurological comorbidity $(\mathrm{G}-\mathrm{W}=0.51, P>0.05)$, or individual types of neurological comorbidity $\left(\chi^{2}=12.15, P>0.05\right)$. Similarly, the presence of a nonneurological comorbidity did not affect overall duration (G-W $=0.78, P>0.05)$. Nevertheless, when data were grouped according to the presence of CVD, arterial hypertension, or neither of these, duration was reduced in the hypertensive group (Figure 3$)\left(\chi^{2}=8.50\right.$, $P<0.05)$.

The results of the Cox regression analysis for demographic variables, Apo E genotype, and the neuropathological variables are shown in Table 3 . The data suggest that (1) patient age had no significant effect on duration, (2) disease onset was significantly associated with duration, earlyonset cases exhibiting better survival $(t=4.12$, Wald statistic $=$ 16.98, and $P<0.01$ ), (3) Apo E score and brain weight were unrelated to duration, and (3) neither total number of areas affected by SP/NFT nor overall severity of pathology was significantly related to duration. The effect of disease onset was similar regardless of whether the PSEN mutation cases were included in the analysis $(t=4.75, P<0.001)$.

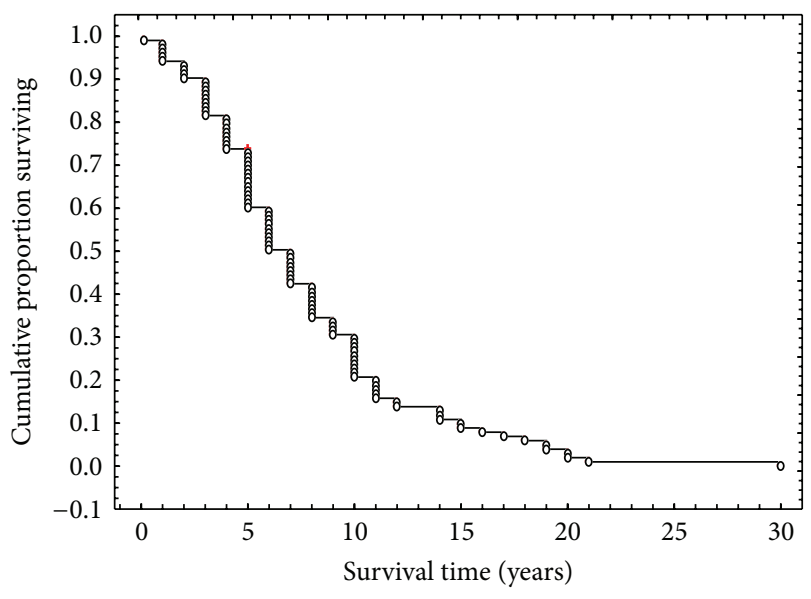

FIGURE 1: Kaplan-Meier survival function of all 103 Alzheimer's disease $(\mathrm{AD})$ patients.

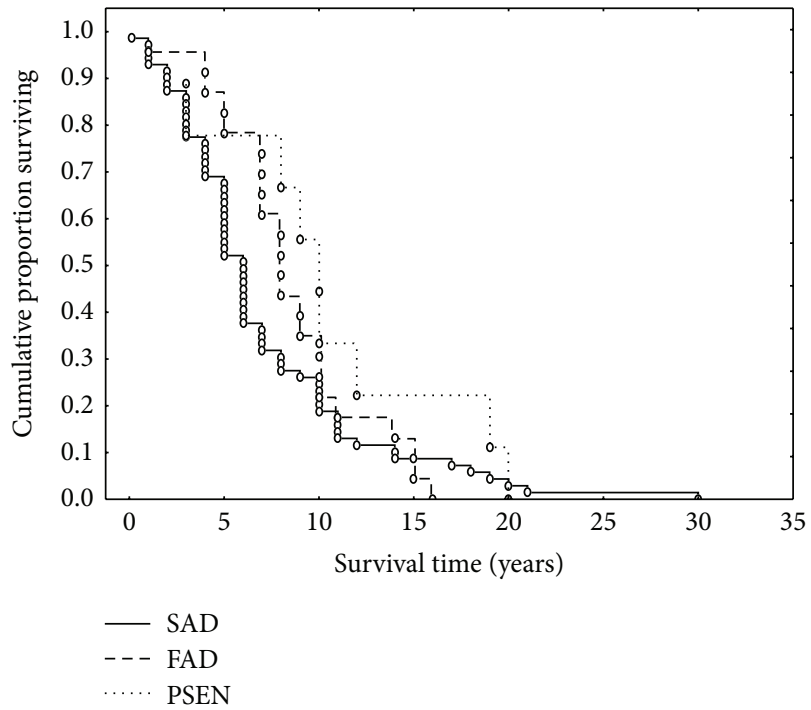

FIGURE 2: Kaplan-Meier survival function of the data grouped into familial Alzheimer's disease (FAD), sporadic Alzheimer's disease (SAD), and familial cases linked to presenilin (PSEN) mutations (comparison between groups: $\chi^{2}=7.13, P<0.01$ ).

The results of the Cox regression analysis of the SP/NFT scores from each brain area studied are shown in Table 4. Of the 22 areas examined, increasing disease duration was associated with increased abundance scores of SP/NFT in three specific areas, namely, the orbital gyrus (OrG) $(t=2.03$, Wald statistic $=4.12$, and $P<0.05)$, CA1 sector of the hippocampus $(t=2.04$, Wald statistic $=4.18$, and $P<0.05)$, and nucleus basalis of Meynert $(\mathrm{NBM})(t=2.09$, Wald statistic $=$ 4.38, and $P<0.05)$.

\section{Discussion}

Mean disease duration of the 103 AD cases studied was 7.1 years slightly higher than the 5.2 years and 6.5 years recorded 


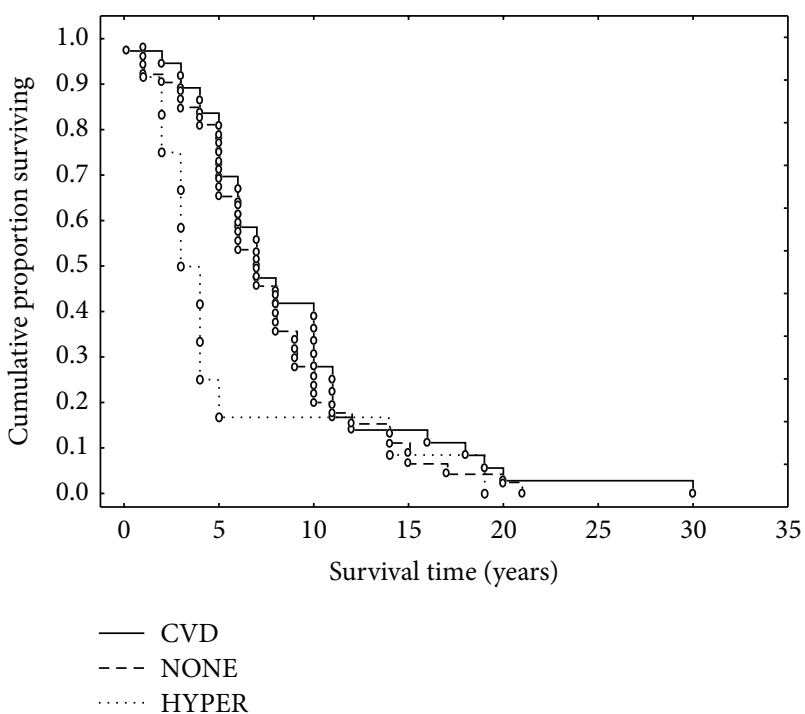

FIGURE 3: Kaplan-Meier survival function of the data grouped into those Alzheimer's disease (AD) patients with no associated signs of cardiovascular disease (NONE), those with the signs of cardiovascular disease (CVD), and those with arterial hypertension (HYPER) (comparison between groups: $\chi^{2}=8.50, P<0.05$ ).

TABLE 3: Results of the Cox proportional hazard model analysis for demographic, apolipoprotein E (Apo E) score, overall severity of neuropathology, and comorbidity (the frequency of neurological and nonneurological comorbidities present in each case).

\begin{tabular}{|c|c|c|c|c|c|}
\hline Variable & $\beta$ & SE & $t$ & Wald & $P$ \\
\hline Patient age & -0.005 & 0.01 & 0.47 & 0.99 & 0.64 \\
\hline Disease onset (all cases) & 0.049 & 0.01 & 4.12 & 16.98 & $0.008^{* *}$ \\
\hline $\begin{array}{l}\text { Disease onset } \\
\text { (minus PSEN cases) }\end{array}$ & 0.055 & 0.012 & 4.75 & 22.61 & $<0.001$ \\
\hline Brain weight & 0.001 & 0.0009 & 0.62 & 0.38 & 0.54 \\
\hline Apo E score & 0.079 & 0.27 & 0.29 & 0.08 & 0.77 \\
\hline Number of areas affected & -0.002 & 0.056 & 0.04 & 0.001 & 0.97 \\
\hline Overall severity score & -0.011 & 0.058 & 0.19 & 0.03 & 0.85 \\
\hline $\begin{array}{l}\text { Neurological } \\
\text { comorbidity }\end{array}$ & 0.131 & 0.136 & 0.96 & 0.93 & 0.33 \\
\hline $\begin{array}{l}\text { Nonneurological } \\
\text { comorbidity }\end{array}$ & 0.032 & 0.081 & 0.40 & 0.16 & 0.70 \\
\hline
\end{tabular}

$\beta$ : regression coefficient; SE: standard error; $P$ : probability; ${ }^{* *} P<0.01$.

by Doody et al. [29] and Feldman et al. [30], respectively. The data also contrast with those reported for a specific group of $\mathrm{AD}$ cases, namely, those with vascular disease comorbidity, in which mean survival was less than five years [30], and semantic dementia (SD), in which $50 \%$ of patients survived more than 12.8 years [20]. In addition, although controversial, recent evidence supports the presence of two distinct subtypes of $\mathrm{AD}$ progression [17], cases having either a very short (median survival 10 months) or a significantly longer disease duration. $\mathrm{AD}$ cases with very short durations were evident in the present sample, 10 cases surviving two years or less. A multiple discriminant analysis comparing these 10 cases with
TABLE 4: Results of the Cox proportional hazard model analysis for abundance scores of senile plaques (SP) and neurofibrillary tangles (NFT) in each brain region.

\begin{tabular}{|c|c|c|c|c|c|}
\hline Area & $\beta$ & SE & $t$ & Wald & $P$ \\
\hline Superior frontal gyrus & -0.00329 & 0.01 & 0.31 & 0.098 & 0.75 \\
\hline Cingulate gyrus & -0.00998 & 0.02 & 0.44 & 0.99 & 0.66 \\
\hline Orbital gyrus & 0.02039 & 0.01 & 2.03 & 4.12 & $0.04^{*}$ \\
\hline Gyrus rectus & -0.1717 & 0.03 & 0.62 & 0.98 & 0.53 \\
\hline Amygdala & 0.01040 & 0.01 & & 1.01 & 0.19 \\
\hline Dent & .00544 & 0.03 & & 1.00 & 0.85 \\
\hline Insula & -0.0 & 0.01 & & 0.07 & 0.79 \\
\hline Claustr & 0.03414 & 0.02 & 1.71 & 2.92 & 0.09 \\
\hline Parahippoc & -0.00190 & 0.01 & 0.17 & 0.03 & 0.86 \\
\hline Hipp & 0.03575 & 0.02 & 2.04 & 4.18 & $0.04^{*}$ \\
\hline Super & & & & & 0.46 \\
\hline Ventral tegment & 0.00470 & 0.02 & 0.26 & 1.00 & 0.80 \\
\hline Raphe nucleus & -0.02172 & 0.02 & 1.11 & 1.24 & 0.27 \\
\hline Subs & 0.02086 & 0.04 & 0.47 & 0.22 & 0.64 \\
\hline Thalamus & -0.02530 & & & .51 & 0.11 \\
\hline Visual cort & -0.00912 & 0.01 & & 0.95 & 0.33 \\
\hline Superior parietal & -0.01378 & 0.01 & 1.42 & 2.02 & 0.15 \\
\hline Nucleus basalis of Meynert & 0.03978 & 0.02 & 2.09 & 4.38 & $0.04^{*}$ \\
\hline Mamillary b & 0.01486 & 0.02 & 0.78 & 0.59 & 0.44 \\
\hline Hypothalamus & 0.01424 & 0.02 & 063 & 0.40 & 0.53 \\
\hline Basal ganglia & -0.02667 & 0.02 & 1.17 & 1.37 & 0.24 \\
\hline Cerebellar cortex & -0.0297 & 0.02 & 1.41 & 1.97 & 0.16 \\
\hline
\end{tabular}

$\beta$ : regression coefficient; SE: standard error; $P$ : probability; ${ }^{*} P<0.05$.

the remainder suggested that short duration was not related to age, onset, brain weight, neuropathology, or comorbidity. The rapidly progressive form of $\mathrm{AD}$ has been linked to increased levels of education and to be associated with a more global cognitive impairment [31]. In addition, a strong correlation between $\mathrm{AD}$ survival and rate of cognitive decline was reported by Hui et al. [32]. By contrast, Bruandet et al. [33] found that highly educated individuals with $\mathrm{AD}$ had a faster rate of cognitive decline but did not have reduced survival times. A limitation of the study is that no accurate data were available on the education level of sufficient cases to test this hypothesis. Alternatively, timing to onset of clinical diagnosis may be related to undiagnosed pathology such as vascular disease or spongiform change.

No significant differences in duration were observed between males and females. This result contrasts with some earlier studies which often show poorer survival in males $[1,29,34,35]$. However, the data suggested longer disease duration in FAD than SAD, especially in cases linked to PSEN mutations. Variation in survival rates between FAD and SAD could result from differences in neuropathology. Hence, cases linked to PSEN1 have greater numbers of SP and NFT compared with cases of SAD [36] but this increased pathology would be expected to shorten survival rates. In addition, many studies suggest that FAD and SAD have essentially the same pathology [37-39]. The most likely explanation for the longer duration of the FAD cases is either earlier disease onset or reduced survival in SAD as a consequence of comorbidity. 
Various types of neurological comorbidity were not associated with shorter durations, in contrast with the study of Feldman et al. [30], which showed reduced survival in cases with associated vascular dementia. Similarly, the presence/absence of nonneurological comorbidity did not reduce survival. In previous studies, the presence of at least one disease complication decreased lifespan in $\mathrm{AD}$ [40] and the presence of comorbidity and functional disability was an important predictor of survival [21]. Bowen et al. [1] found a strong association between decreased survival in $\mathrm{AD}$ and vascular disease which is regarded as a significant determinant of progression to dementia. A limitation of the present study is that accurate quantitative data on CVD load, for example, lacunar infarcts, microinfarcts, and atherosclerosis of large vessels, was not available. However, in the present study, the presence/absence of CVD was not associated with disease duration. Nevertheless, there was evidence of reduced disease duration in those $\mathrm{AD}$ cases with arterial hypertension when compared with those with CVD or neither of these conditions. Hypertension is a strong risk factor for stroke, heart disease, aneurysm, and chronic kidney disease but the sample of cases was too small to test whether hypertensive individuals had increased incidence of these pathologies. A strong correlation between the presence of atherosclerosis and mortality in $\mathrm{AD}$ [41] and between survival and severe arterial hypertension, measured at the beginning of the study [19], has been demonstrated in AD. By contrast, Weiner and Risser [42] found no effect of CVD or hypertension on AD survival. In addition, no association between survival and CVD was found in a cohort of Down's syndrome (DS) patients [43], who frequently develop AD-type pathology [44-46].

No association was observed between disease duration and Apo E genotype of the patient. This is surprising as the presence of allele $\varepsilon 4$ often accelerates the development of $\mathrm{AD}$ pathology [47] and hence is associated with an earlier disease onset [48]. Apo E genotype was available for only 40 of the cases studied, which was too small a sample size to determine the true effect of this variable. In the rapidly progressive form of $\mathrm{AD}$, however, no association with Apo $E$ allele $\varepsilon 4$ and survival was reported [18]. By contrast, Tilvis et al. [49] found that the presence of $A$ po $E \varepsilon 4$ allele was associated with impaired cognitive function and clinical dementia and hence could be associated with reduced survival.

Whether the degree of brain atrophy and weight significantly change over the course of $\mathrm{AD}$ has been controversial. There are significant limitations in studying this complex variable as many factors may influence brain weight such as height of the subject and the degree of osteoporosis. In one study, poorer survival was associated with lower gray matter volume and smaller volume reductions in brain predicted better survival [50]. In the present study, no relationship between brain weight and disease duration was demonstrated. In addition, neither total number of areas affected by SP/NFT pathology nor an overall measure of severity of the pathology was associated with disease duration suggesting neuropathology does not directly affect survival. Nevertheless, data suggest an association between SP/NFT pathology in the OrG, sector CA1 of the hippocampus, and NBM and longer disease durations consistent with spread of the pathology into these areas later in the disease. Alternatively, correlation of longer duration to pathology may result from regions being the earliest affected and therefore exposed to accumulating pathology over periods of time. Several studies suggest that the pathology of AD may spread through the brain via anatomical connections from an origin in the temporal lobe to the cortical association areas and hippocampus and then to the primary sensory areas [51-55]. In addition, pathogenic proteins, such as tau, $\alpha$-synuclein, and $\beta$-amyloid (A $\beta)$, can be secreted from cells, enter other cells, and seed small intracellular aggregates within these cells $[56,57]$ and therefore could spread through the brain.

In conclusion, the data suggest disease duration of $\mathrm{AD}$ patients is reduced in SAD and especially in cases with associated arterial hypertension. By contrast, sex, neurological comorbidity, brain weight, Apo E genotype, and neuropathology had little effect on survival. Longer duration cases, however, were associated with spread of SP/NFT pathology into the frontal lobe, hippocampus, and basal forebrain.

\section{Conflict of Interests}

The author declares that there is no conflict of interests regarding the publication of this paper.

\section{Acknowledgment}

The assistance of members of the Department of Neuropathology, University of Washington, Seattle, USA, in providing the cases for this study is gratefully acknowledged.

\section{References}

[1] J. D. Bowen, A. D. Malter, L. Sheppard et al., "Predictors of mortality in patients diagnosed with probable Alzheimer's disease," Neurology, vol. 47, no. 2, pp. 433-439, 1996.

[2] A. Ueki, H. Shinjo, H. Shimode, T. Nakajima, and Y. Morita, "Factors associated with mortality in patients with early-onset Alzheimer's disease: a five-year longitudinal study," International Journal of Geriatric Psychiatry, vol. 16, no. 8, pp. 810-815, 2001.

[3] H. Brodaty, K. Seeher, and L. Gibson, "Dementia time to death: a systematic literature review on survival time and years of life lost in people with dementia," International Psychogeriatrics, vol. 24, pp. 1034-11045, 2012.

[4] R. A. Armstrong and D. Myers, "Principal components analysis of Alzheimer's disease based on neuropathological data: a study of 79 patients," Neuroscience Research Communications, vol. 11, no. 1, pp. 1-9, 1992.

[5] R. A. Armstrong and L. Wood, "The identification of pathological subtypes of Alzheimer's disease using cluster analysis," Acta Neuropathologica, vol. 88, no. 1, pp. 60-66, 1994.

[6] R. A. Armstrong, D. Nochlin, and T. D. Bird, "Neuropathological heterogeneity in Alzheimer's disease: a study of 80 cases using principal components analysis," Neuropathology, vol. 20, no. 1, pp. 31-37, 2000.

[7] H. C. Chui, E. L. Teng, V. W. Henderson, and A. C. Moy, "Clinical subtypes of dementia of the Alzheimer type," Neurology, vol. 35, no. 11, pp. 1544-1550, 1985. 
[8] M.-C. Chartier-Harlin, F. Crawford, H. Houlden et al., "Earlyonset Alzheimer's disease caused by mutations at codon 717 of the $\beta$-amyloid precursor protein gene," Nature, vol. 353, no. 6347, pp. 844-846, 1991.

[9] A. Goate, M.-C. Chartier-Harlin, M. Mullan et al., "Segregation of a missense mutation in the amyloid precursor protein gene with familial Alzheimer's disease," Nature, vol. 349, no. 6311, pp. 704-706, 1991.

[10] R. Sherrington, E. I. Rogaev, Y. Liang et al., "Cloning of a gene bearing missense mutations in early-onset familial Alzheimer's disease," Nature, vol. 375, no. 6534, pp. 754-760, 1995.

[11] E. Levy-Lahad, W. Wasco, P. Poorkaj et al., "Candidate gene for the chromosome 1 familial Alzheimer's disease locus," Science, vol. 269, no. 5226, pp. 973-977, 1995.

[12] W. J. Strittmatter, K. H. Weisgraber, D. Y. Huang et al., "Binding of human apolipoprotein $\mathrm{E}$ to synthetic amyloid $\beta$ peptide: isoform-specific effects and implications for late-onset Alzheimer disease," Proceedings of the National Academy of Sciences of the United States of America, vol. 90, no. 17, pp. 8098-8102, 1993.

[13] F. Boller, “Alzheimer's disease and Parkinson's disease: clinical and pathological associations," in Alzheimer's Disease. The Standard Reference, B. Reisberg, Ed., pp. 295-302, MacMillan, London, UK, 1983.

[14] D. W. Dickson, D. Ruan, H. Crystal et al., "Hippocampal degeneration differentiates diffuse Lewy body disease (DLBD) from Alzheimer's disease: light and electron microscopic immunocytochemistry of CA2-3 neurites specific to DLBD," Neurology, vol. 41, no. 9, pp. 1402-1409, 1991.

[15] A. Brun and E. Englund, "A white matter disorder in dementia of the Alzheimer type: a pathoanatomical study," Annals of Neurology, vol. 19, no. 3, pp. 253-262, 1986.

[16] N. L. Komarova and C. J. Thalhauser, "High degree of heterogeneity in Alzheimer's disease progression patterns," PLOS Comparative Biology, vol. 7, Article ID e1002251, 2011.

[17] C. J. Thalhauser and N. L. Komarova, "Alzheimer's disease: rapid and slow progression," Journal of the Royal Society Interface, vol. 9, no. 66, pp. 119-126, 2012.

[18] C. Schmidt, S. Haik, K. Satoh, A. Rabano, P. Martinez-Martin, S. Roeber et al., "Rapidly progressive Alzheimer's disease: a multicenter update," Journal of Alzheimer's Disease, vol. 30, pp. 751756, 2010.

[19] R. Nitrini, P. Caramelli, E. Herrera Jr. et al., "Mortality from dementia in a community-dwelling Brazilian population," International Journal of Geriatric Psychiatry, vol. 20, no. 3, pp. 247253, 2005.

[20] J. R. Hodges, J. Mitchell, K. Dawson et al., "Semantic dementia: demography, familial factors and survival in a consecutive series of 100 cases," Brain, vol. 133, no. 1, pp. 300-306, 2010.

[21] D. Zekry, F. R. Herrmann, C. E. Graf et al., "High levels of comorbidity and disability cancel out the dementia effect in predictions of long-term mortality after discharge in the very old," Dementia and Geriatric Cognitive Disorders, vol. 32, no. 2, pp. 103-110, 2011.

[22] M. C. Tierney, R. H. Fisher, A. J. Lewis et al., "The NINCDSADRDA Work Group criteria for the clinical diagnosis of probable Alzheimer's disease: a clinicopathologic study of 57 cases," Neurology, vol. 38, no. 3, pp. 359-364, 1988.

[23] S. S. Mirra, A. Heyman, D. McKeel et al., "The Consortium to Establish a Registry for Alzheimer's Disease (CERAD). Part II. Standardization of the neuropathologic assessment of Alzheimer's disease," Neurology, vol. 41, no. 4, pp. 479-486, 1991.
[24] M. Ball, H. Braak, P. Coleman et al., "Consensus recommendations for the postmortem diagnosis of Alzheimer's disease," Neurobiology of Aging, vol. 18, no. 4, pp. S1-S2, 1997.

[25] H. Braak and E. Braak, "Neuropathological stageing of Alzheimer-related changes," Acta Neuropathologica, vol. 82, no. 4, pp. 239-259, 1991.

[26] H. Braak, I. Alafuzoff, T. Arzberger, H. Kretzschmar, and K. del Tredici, "Staging of Alzheimer disease-associated neurofibrillary pathology using paraffin sections and immunocytochemistry," Acta Neuropathologica, vol. 112, no. 4, pp. 389-404, 2006.

[27] Z. S. Khatchaturian, "Diagnosis of Alzheimer's disease," Archives of Neurology, vol. 42, pp. 1097-1005, 1985.

[28] R. A. Armstrong, "Quantifying the pathology of neurodegenerative disorders: quantitative measurements, sampling strategies and data analysis," Histopathology, vol. 42, no. 6, pp. 521-529, 2003.

[29] R. Doody, V. Pavlik, P. Massman et al., "Changing patient characteristics and survival experience in an Alzheimer's center patient cohort," Dementia and Geriatric Cognitive Disorders, vol. 20, no. 2-3, pp. 198-208, 2005.

[30] H. H. Feldman, T. Pirttila, J. F. Dartigues et al., "Analyses of mortality risk in patients with dementia treated with galantamine," Acta Neurologica Scandinavica, vol. 119, no. 1, pp. 22-31, 2009.

[31] M. Musicco, G. Salamone, C. Caltagirone et al., "Neuropsychological predictors of rapidly progressing patients with Alzheimer's disease," Dementia and Geriatric Cognitive Disorders, vol. 30, no. 3, pp. 219-228, 2010.

[32] J. S. Hui, R. S. Wilson, D. A. Bennett, J. L. Bienias, D. W. Gilley, and D. A. Evans, "Rate of cognitive decline and mortality in Alzheimer's disease," Neurology, vol. 61, no. 10, pp. 1356-1361, 2003.

[33] A. Bruandet, F. Richard, S. Bombois et al., "Cognitive decline and survival in Alzheimer's disease according to education level," Dementia and Geriatric Cognitive Disorders, vol. 25, no. 1, pp. 74-80, 2008.

[34] G. Gambassi, K. L. Lapane, F. Landi, A. Sgadari, V. Mor, and R. Bernabei, "Gender differences in the relation between comorbidity and mortality of patients with Alzheimer's disease," Neurology, vol. 53, no. 3, pp. 508-516, 1999.

[35] J. J. Claus, W. A. van Gool, S. Teuniss et al., "Predicting survival in patients with early Alzheimer's disease," Dementia and Geriatric Cognitive Disorders, vol. 9, no. 5, pp. 284-293, 1998.

[36] C. E. Shepherd, G. C. Gregory, J. C. Vickers et al., "Positional effects of presenilin-1 mutations on tau phosphorylation in cortical plaques," Neurobiology of Disease, vol. 15, no. 1, pp. 115-119, 2004.

[37] M. Haupt, A. Kurz, S. Pollmann, and B. Romero, "Alzheimer's disease: identical phenotype of familial and non-familial cases," Journal of Neurology, vol. 239, no. 5, pp. 248-250, 1992.

[38] D. Nochlin, G. van Belle, D. Bird, and S. M. Sumi, "Comparison of the severity of neuropathologic changes in familial add sporadic Alzheimer's disease," Alzheimer Disease and Associated Disorders, vol. 7, no. 4, pp. 212-222, 1993.

[39] R. A. Armstrong, "Spatial patterns of $\beta$-amyloid (A $\beta)$ deposits in familial and sporadic Alzheimer's disease," Folia Neuropathologica, vol. 49, no. 3, pp. 153-161, 2011.

[40] B. Zhou, Q. H. Zhao, S. Teramukai et al., "Executive function predicts survival in Alzheimer disease: a study in Shanghai," Journal of Alzheimer's Disease, vol. 22, no. 2, pp. 673-682, 2010.

[41] M. van Oijen, F. J. de Jong, J. C. M. Witteman, A. Hofman, P. J. Koudstaal, and M. M. B. Breteler, "Atherosclerosis and risk for dementia," Annals of Neurology, vol. 61, no. 5, pp. 403-410, 2007. 
[42] M. F. Weiner and R. C. Risser, "Effect of educational attainment on survival in Alzheimer's disease," Alzheimer's Reports, vol. 1, no. 6, pp. 369-374, 1998.

[43] A. M. W. Coppus, H. M. Evenhuis, G.-J. Verberne et al., "Survival in elderly persons with down syndrome," Journal of the American Geriatrics Society, vol. 56, no. 12, pp. 2311-2316, 2008.

[44] D. M. A. Mann and M. M. Esiri, "The pattern of acquisition of plaques and tangles in the brains of patients under 50 years of age with Downs' syndrome," Journal of the Neurological Sciences, vol. 89, no. 2-3, pp. 169-179, 1989.

[45] D. M. A. Mann, N. Younis, D. Jones, and R. W. Stoddart, "The time course of the pathological events in Down's syndrome with particular reference to the involvement of microglial cells and deposits of o $\beta / A 4$," Neurodegeneration, vol. 1, pp. 201-215, 1992.

[46] J. Motte and R. S. Williams, "Age-related changes in the density and morphology of plaques and neurofibrillary tangles in Down syndrome brain," Acta Neuropathologica, vol. 77, no. 5, pp. 535546, 1989.

[47] F. Oyama, H. Shimada, R. Oyama, and Y. Ihara, "Apolipoprotein E genotype, Alzheimer's pathologies and related gene expression in the aged population," Molecular Brain Research, vol. 29, no. 1, pp. 92-98, 1995.

[48] T. Gomez-Isla, H. L. West, G. W. Rebeck et al., "Clinical and pathological correlates of apolipoprotein $\varepsilon 4$ in Alzheimer's disease," Annals of Neurology, vol. 39, no. 1, pp. 62-70, 1996.

[49] R. S. Tilvis, T. E. Strandberg, and K. Juva, "Apolipoprotein E phenotypes, dementia and mortality in a prospective population sample," Journal of the American Geriatrics Society, vol. 46, no. 6, pp. 712-715, 1998.

[50] R. T. Staff, A. D. Murray, T. Ahearn et al., "Brain volume and survival from age 78 to 85 : the contribution of alzheimer-type magnetic resonance imaging findings," Journal of the American Geriatrics Society, vol. 58, no. 4, pp. 688-695, 2010.

[51] R. C. A. Pearson, M. M. Esiri, and R. W. Hiorns, "Anatomical correlates of the distribution of the pathological changes in the neocortex in Alzheimer disease," Proceedings of the National Academy of Sciences of the United States of America, vol. 82, no. 13, pp. 4531-4534, 1985.

[52] R. A. Armstrong, D. Myers, and C. U. M. Smith, "Alzheimer's disease: size class frequency distribution of senile plaques: do they indicate when a brain tissue was affected?" Neuroscience Letters, vol. 127, no. 2, pp. 223-226, 1991.

[53] M.-C. de Lacoste and C. L. White III, "The role of cortical connectivity in Alzheimer's disease pathogenesis: a review and model system," Neurobiology of Aging, vol. 14, no. 1, pp. 1-16, 1993.

[54] R. A. Armstrong and A. Slaven, "Does the neurodegeneration of Alzheimer's disease spread between visual cortical regions B17 and B18 via the feedforward or feedback short cortico-cortical projections?” Neurodegeneration, vol. 3, pp. 191-196, 1994.

[55] R. A. Armstrong and N. J. Cairns, "Different molecular pathologies result in similar spatial patterns of cellular inclusions in neurodegenerative disease: a comparative study of eight disorders," Journal of Neural Transmission, vol. 119, pp. 1551-1560, 2012.

[56] M. Goedert, F. Clavaguera, and M. Tolnay, "The propagation of prion-like protein inclusions in neurodegenerative diseases," Trends in Neurosciences, vol. 33, no. 7, pp. 317-325, 2010.

[57] J. A. Steiner, E. Angot, and P. Brundin, "A deadly spread: cellular mechanisms of $\alpha$-synuclein transfer," Cell Death and Differentiation, vol. 18, no. 9, pp. 1425-1433, 2011. 


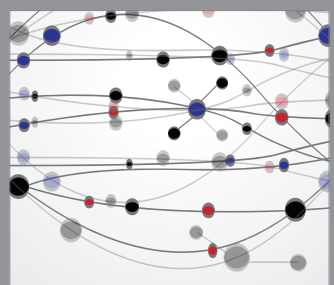

The Scientific World Journal
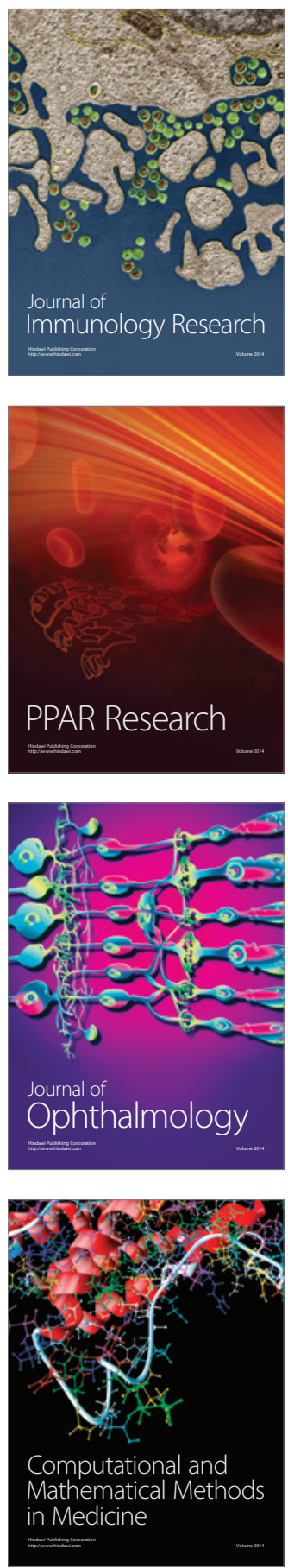

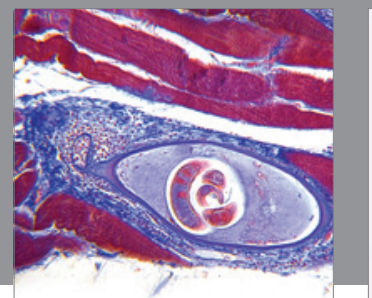

Gastroenterology

Research and Practice
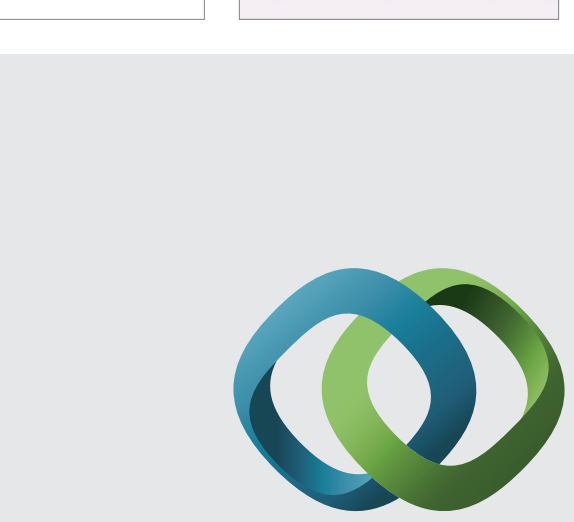

\section{Hindawi}

Submit your manuscripts at

http://www.hindawi.com
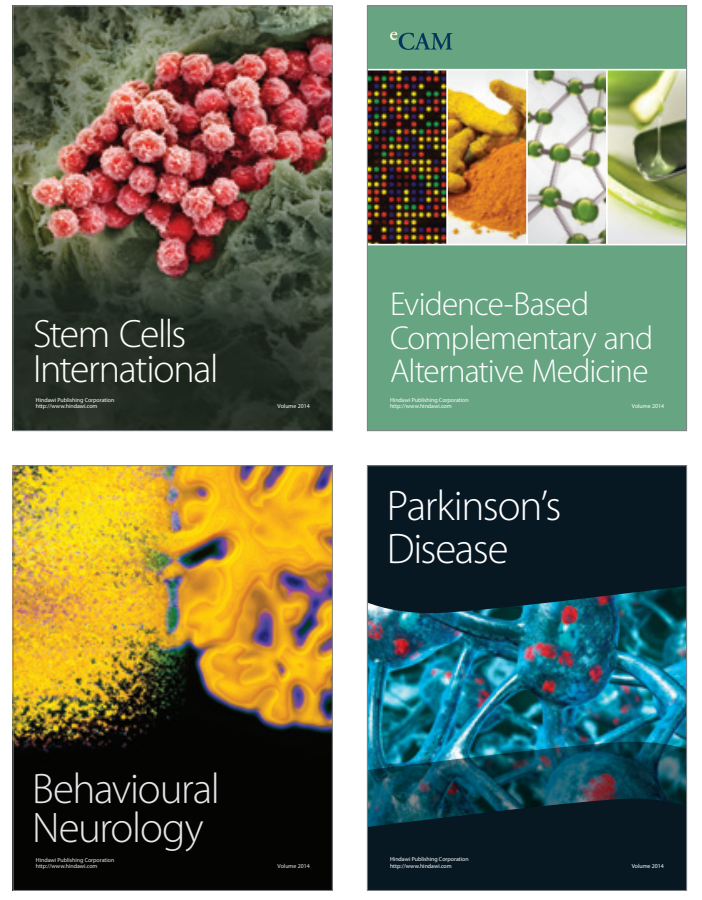
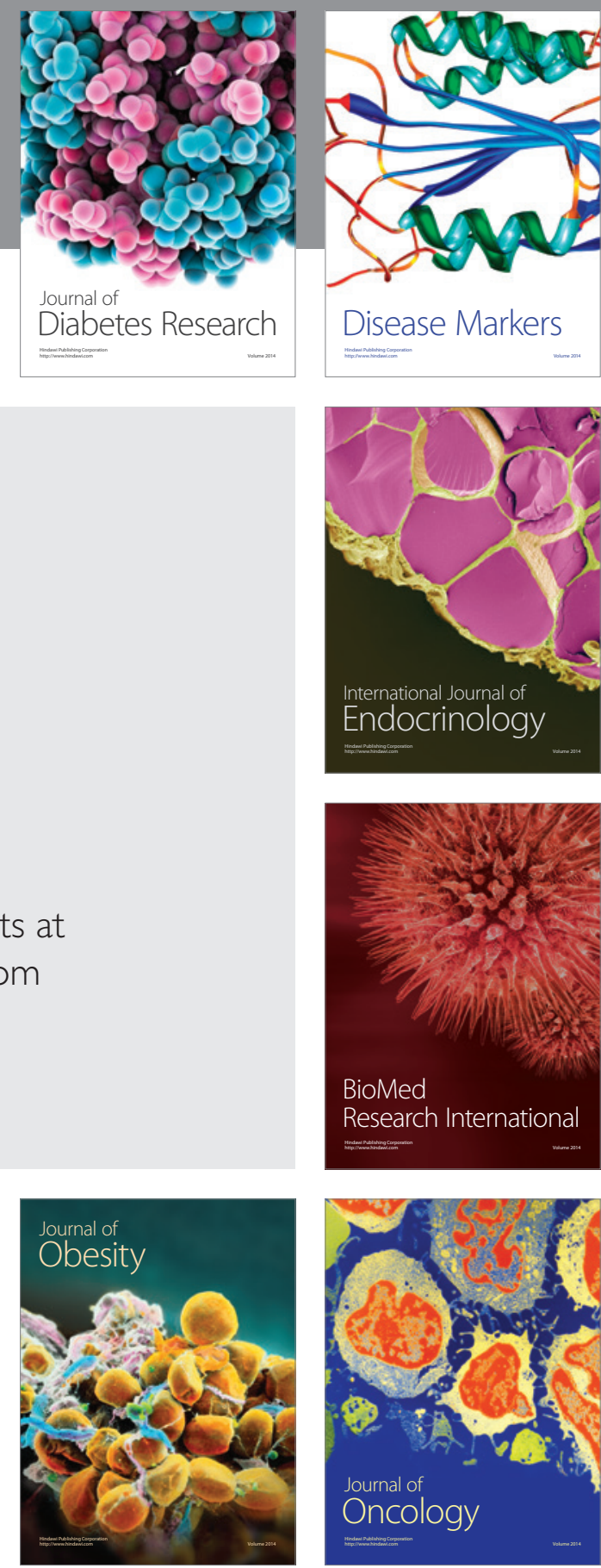

Disease Markers
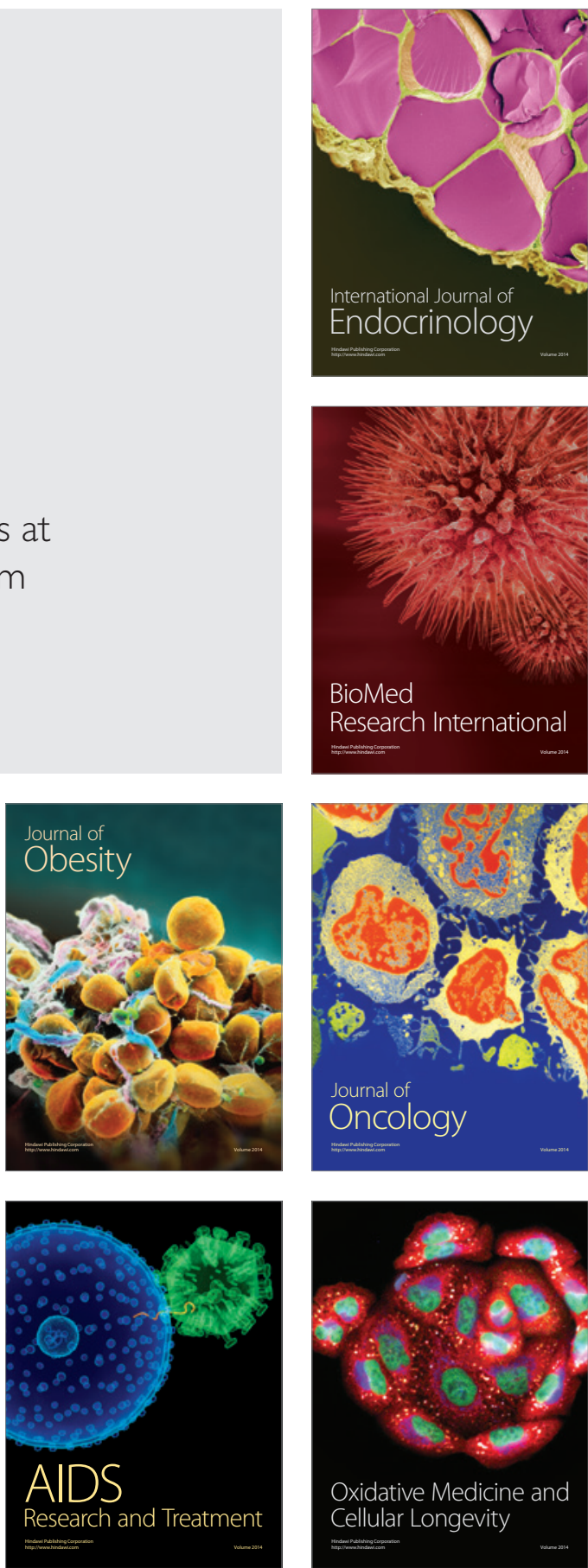